\title{
A Review on use of Sunlight in Human Life
}

\author{
Md Belal Bin Heyat ${ }^{1}$ \\ Department of ECE \\ Glocal University, Saharanpur, India
}

\author{
Faijan Akhtar ${ }^{2}$ \\ Department of CSE \\ Jamia Hamdard, New Delhi, India
}

\author{
Shajan Azad $^{3}$ \\ Department of Nursing \\ HIN \& Hospital, Lucknow, India
}

\begin{abstract}
Sun maked by God, Some sun light is use in the treatment of human disease. Sun light application in human life likegendis of children, cook food, dry clothes, design passive solar home, electricity and photosynthesis of the plant i.e. human is use in plant in breathing of human such as $\mathrm{O} 2$ and food in vegetable form.
\end{abstract}

\section{INTRODUCTION}

Sun is the astronomical at the midpoint of the astral arrangement. It is a virtually perfect range of warm plasma, with inner convectivegesture that produces an attractive field via an electric generatorprocedure. The most significant source of vigor for life expectancy on dirt. Its length is nearby one hundred nine periods that of Dirt \&corpus is around 330,000 periods that of Dirt, secretarial for nearby 99.86 percent of the entire mass of the solar System.

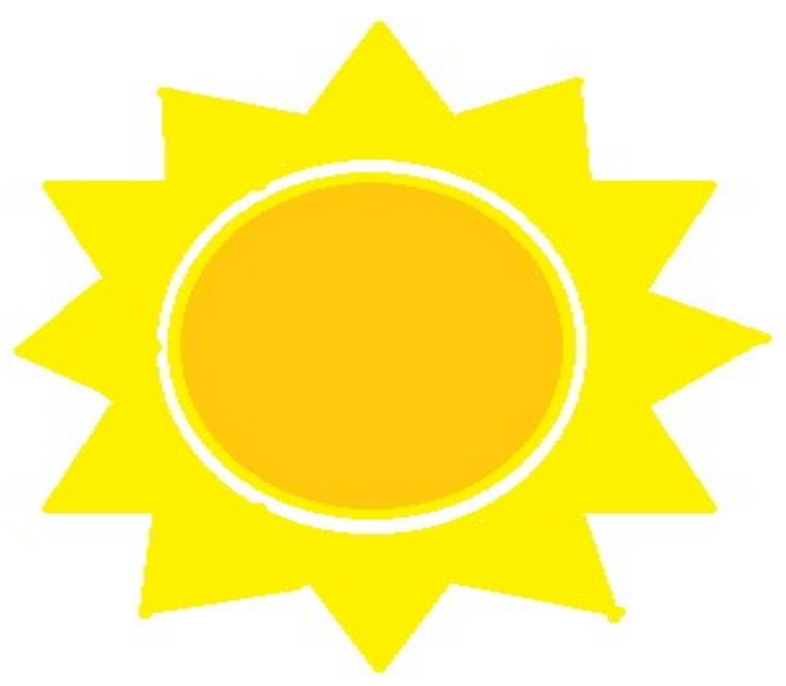

Fig 1:Picture of Sun

Solar energy can be equally good and wicked for a human fitness. When in the sunny, the human figure uses the UV part of sunshine to variety its own Vitamin D. Without sunblock, ultraviolet sunny can cause suntan and skin growth. Angle of occurrence of the sunshine makes alteration in periods on Mud as healthy as in the distance of daytime and nightly.

\section{SUN LIGHT}

Sunlight is the nimble and vigor that originates from the sun. While this vigor reaches the muds superficial, it is called as insolation. It is the radioactivity and warmness from the sun in the procedure of electromagnetic influences. The air affects the quantity of solar energy established. While solar energy travels concluded the air, the air engrosses some of it. Some of it is dispersed to galaxy. Some of it is reproduced by vapors. Around $47 \%$ of it spreads the Ground's surface.Florae need rays for the procedure of photosynthesis. Throughoutphotosynthesis, the florae use the vigor of the sunshine, $\mathrm{H}_{2} \mathrm{O}$ (water), and $\mathrm{CO}_{2}$ (Carbon di oxide), to create $\mathrm{C}_{6} \mathrm{H}_{12} \mathrm{O}_{6}$ (Glucose). The $\mathrm{C}_{6} \mathrm{H}_{12} \mathrm{O}_{6}$ (Glucose)can advanced be charity by the vegetal for wildlife eatsor vigor. The vegetal and the $\mathrm{C}_{6} \mathrm{H}_{12} \mathrm{O}_{6}$ (Glucose) in it. Florae need sunshine to producegreen. Wanting enough sunshine but with sufficient water, the vegetalproduces very tall actual quickly, but expressions yellow and parched, although when warmed, the leaves are actual moist.Solar radiometer is an expedient that exactly measures the sunlight's strength.The distance of Sun and Earth is One hundred forty nine point six million kilometer, the sun light reached in the earth from Eight minute \& Twenty seconds.

* Color of Sun Light-Yellow, Orange, Red, Green, Violet, Blue, White

\section{A. Planets in Solar System}

The all planets is around the sun-

Table1: Planets in Solar System

\begin{tabular}{|c|c|c|c|c|}
\hline Planet & $\begin{array}{l}\text { Distance from } \\
\text { the Sun (mK) }\end{array}$ & $\begin{array}{l}\text { Rotation } \\
\text { Period }\end{array}$ & $\begin{array}{c}\text { Diamete } \\
\mathrm{r} \\
(\mathrm{Km})\end{array}$ & $\begin{array}{c}\text { Temp } \\
(\mathrm{k})\end{array}$ \\
\hline Earth & 149.6 & 24 hours & 12576 & $\begin{array}{c}260- \\
310\end{array}$ \\
\hline Jupiter & 778.3 & $\begin{array}{c}9.84 \text { Earth } \\
\text { hours }\end{array}$ & 142.79 & 120 \\
\hline Mars & 227.9 & $\begin{array}{l}\text { 24.6 Earth } \\
\text { hours }\end{array}$ & 6787 & $\begin{array}{l}150- \\
310\end{array}$ \\
\hline $\begin{array}{l}\text { Mercur } \\
\mathrm{y}\end{array}$ & 57.9 & $\begin{array}{c}\text { 58.7 Earth } \\
\text { days }\end{array}$ & 4878 & 452 \\
\hline $\begin{array}{c}\text { Neptun } \\
\text { e }\end{array}$ & 4497.1 & $\begin{array}{c}\text { 19.1 Earth } \\
\text { hours }\end{array}$ & 48600 & 48 \\
\hline
\end{tabular}



www.ijtsrd.com

\begin{tabular}{|lcccc|}
\hline Pluto & 5913 & $\begin{array}{c}\text { 6.39 Earth } \\
\text { days }\end{array}$ & 2274 & 37 \\
\hline Saturn & 1427 & $\begin{array}{c}\text { 10.2 Earth } \\
\text { hours }\end{array}$ & 120660 & 88 \\
\hline Uranus & 2871 & $\begin{array}{c}17.9 \text { Earth } \\
\text { hours }\end{array}$ & 51118 & 59 \\
\hline Venus & 108.2 & $\begin{array}{c}\text { 243 Earth } \\
\text { days }\end{array}$ & 12104 & 726 \\
\hline
\end{tabular}

\section{USES OF SUN LIGHT}

Sun light is use in different human life like energy generation, physical work and treatment of disease like gendis syndrome of children. The some sun light application in human life is given below-

\section{B. Solar Radiation Received by Planet}

Table 2: Solar radiation (Min \& Max) received by planet

\begin{tabular}{|cccc|}
\hline S. No & Name of Planet & \multicolumn{2}{c|}{ Solar Radiation $\left(\mathrm{W} / \mathrm{m}^{2}\right)$} \\
\cline { 3 - 4 } & & Min & Max \\
\hline $\mathbf{1}$ & Earth & 1321 & 1413 \\
\hline $\mathbf{2}$ & Jupiter & 45.9 & 55.8 \\
\hline $\mathbf{3}$ & Mars & 492 & 715 \\
\hline $\mathbf{4}$ & Mercury & 6272 & 14446 \\
\hline $\mathbf{5}$ & Neptune & 1.47 & 1.54 \\
\hline $\mathbf{6}$ & Pluto & 0.57 & 1.55 \\
\hline $\mathbf{7}$ & Saturn & 13.4 & 16.7 \\
\hline $\mathbf{8}$ & Uranus & 3.39 & 4.04 \\
\hline $\mathbf{9}$ & Venus & 2576 & 2647 \\
\hline
\end{tabular}

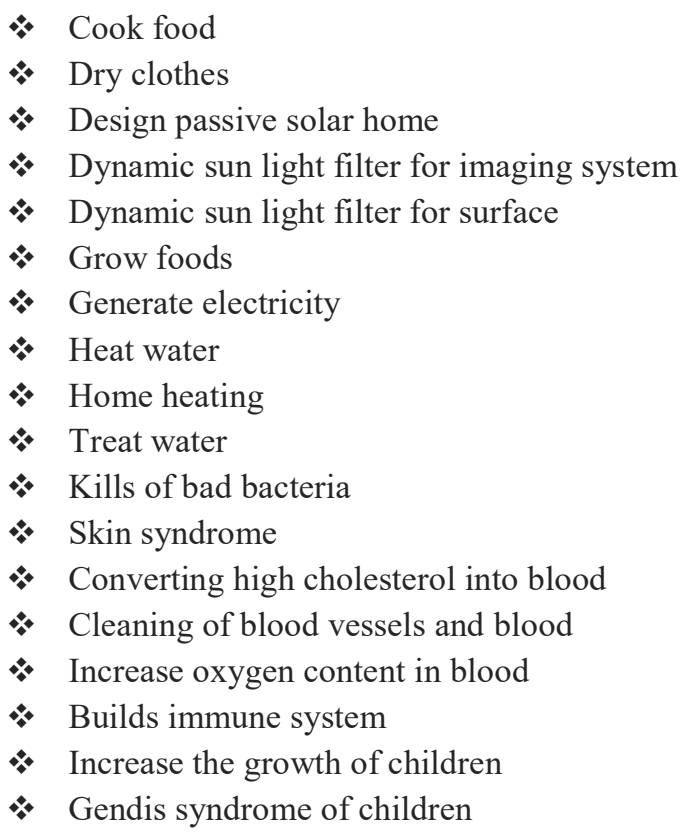

\section{CONCLUSION}

\section{III . VITAMIN-D}

Vitamin D is a kind of vitamin, which does essential to complete from external foundation. It can be fashioned from saturated fatty acid by treatment with sunshine. When the sunny fall on the casing, the ergosterol under the skin changes to vitamin D. Consequently, if somebody stays absent from sunshine for long, he inclines to develop vitamin D shortage. Any other Sources of Vitamin D-

$$
\begin{array}{ll}
* \text { Cereal } \\
* \text { Egg yolk } \\
* \text { Orange } \\
* \text { Milk } \\
\text { * Shrimp } \\
\text { * Sardines } \\
\text { * Shrimp }
\end{array}
$$

The treatment of human in Sun light is decreasing of Vitamin-D in the human body. The sun is best source in Vitamin-D, other sources of Vitamin-D is egg, orange, milk etc. Vitamin-D is very helpful in the bone. On future research sun light are uses in other treatment of human syndrome.

Abbreviations- UV: Ultra Violet; $\mathrm{O}_{2}$ : Oxygen; $\mathrm{H}_{2} \mathrm{O}$ : Water

Competing interests- Md Belal Bin Heyat is a researcher and author asserts that they have no competing interests.

\section{Acknowledgment}

Author \& Co-author thanks to God, Parents mainly my mother RoshanAra, Friends mainly Er Shaguftah, SeemaRajmani, Shahnawaz, Syed Rafi Ahmad and ErShipraSrivastava, Teacher mainly Prof. (Dr) HasinAlam, Prof. (Dr) SerajulHaq, Er Mani Rajput, Prof. (Dr) NaimurRahmanQidwai,ErNaseem Ahmad and Mohd Maroof Siddiqui to help, support \& formatting of Manuscript. 


\section{References}

[1] www.rajaha.com

[2] www.healthline.com

[3] Er. ShipraSrivastava, Mohd Maroof Siddiqui, SaifurRahman, Prof (Dr.) Syed HasanSaeed, Md Belal Bin Heyat, "Carbon Nano tubes \& Its Application In Medical Field \& Communication", International Journal of Advanced Research in Computer and Communication Engineering 2016 May;5(5): pp.170-173.

[4] Md Belal Bin Heyat, Shaguftah, Y.M.Hasan, M.M.Siddiqui, "EEG Signals and Wireless transfer of EEG Signals", International Journal of Advanced Research in Computer and Communication Engineering Volume 2015 December;4(12): pp. 502-504.

[5] Md Belal Bin Heyat, Faijan Akhtar, Mohd Sikandar Hayat Siddiqui, Shafan Azad, "An Overview of Dalk Therapy and treatment of Insomnia by Dalk Therapy", National Seminar on Research Methodology in Ilaj-Bit-Tadbeer, organized by State Takmeel-ut-Tib-College \& Hospital, Lucknow 10 October 2015.

[6] Y.M.Hasan, Md Belal Bin Heyat, M.M.Siddiqui, S.Azad, and F.Akhtar, "An Overview of Sleep and Stages of Sleep", International Journal of Advanced Research in Computer and Communication Engineering, 2015 December;4(12): pp. 505507.

[7] Md Belal Bin Heyat, Mohd Maroof Siddiqui, "Recording of EEG, ECG, EMG Signal", International Journal of Advanced Research in Computer Science and Software Engineering, 2015 October;5(10): pp. 813-815.

[8] Omer Farooq, TouseefRahman, Md Belal Bin Heyat, Mohd Maroof Siddiqui, Faijan Akhtar, "An Overview of NFLE", International Journal of Innovative Research in Electrical, Electronics, Instrumentation \& Control Engg, 2016 March;4(3): pp. 209-211.

[9] TouseefRahman, Omer Farook, Md Belal Bin Heyat, Mohd Maroof Siddiqui, "An Overview of Narcolepsy", International Advanced Research Journal in Science, Engineering and Technology, 2016 March;3(3):pp. 85-87.

[10] Md Belal Bin Heyat, Faijan Akhtar, Shaguftah, Naseem Ahmad, "An Overview of Renewable Energy",International Journal of Technical Research \& Science, Volume 1, Issue 6, September 2016. pp 119-121.
[11] Md Belal Bin Heyat, Shahabaz Ahmad Khan, Ahmad Zakariya, Faijan Akhtar, Shajan Azad"Microcontroller Using Industrial Tank", Onyx Journal of Multi- Disciplines, Onyx InterScience, Vol. 1, Issue 1, October 2016, 5-8.

[12] Md Belal Bin Heyat, Shaguftah, Faijan Akhtar, Mohd Ammar Bin Hayat, Shajan Azad, "Power Spectral Density are used in the Investigation of insomnia neurological disorder", XL PRE-CONGRESS symposium, organized by INDIAN ACADEMY OF SOCIAL SCIENCES [ISSA] in King George Medical University\& State Takmeel-utTibbCollege and Hospital Lucknow.

[13] Shahabaz Ahmad Khan, Ahmad Zakariya, ErSaima Beg, Md Belal Bin Heyat and Mohd Maroof Siddiqui, "Industrial Tank Temperature, Pressure and Humidity Controller Using Microcontroller", National Conference on Emerging Trends in Non Conventional Energy Resources, organized by Integral University, Lucknow, 22 October 2016.

[14] www.en.wikipedia.org/sunlight

[15] www.mindbodygreen.com

[16] KumaravelRajakumar, "Vitamin D, Cod-Liver Oil, Sunlight, and Rickets: A Historical Perspective", Vol. 112, Vol. 112, No. 2, August 2003.

[17] Michael F Holick, "Sunlight and vitamin D for bone health and prevention ofautoimmune diseases, cancers, and cardiovascular disease", The American journal of clinical nutrition, 5 Nov 2016.

[18] www.reference.com

[19] www.enchantedlearning.com 